\title{
MATEMATICANDO: A GEOMETRIA NAS MANDALAS
}

\author{
Mariana Baumhardt Souza ${ }^{1}$ \\ Marli Teresinha Quartieri² \\ Miriam Ines Marchi ${ }^{3}$
}

\begin{abstract}
Resumo: Este artigo pretende socializar os resultados de uma prática pedagógica desenvolvida com alunos do $6^{\circ}$ ano do Ensino Fundamental de uma escola pública, localizada em Porto Alegre/RS. $\mathrm{O}$ objetivo da prática foi propiciar aos alunos atividades que relacionassem conteúdos matemáticos com a arte, por meio da construção de mandalas. Além disso, foram investigados quais conceitos geométricos poderiam emergir durante a realização das atividades propostas, bem como as reaçôes dos alunos durante a efetivaçáo das mesmas. A coleta dos dados foi realizada a partir do diário de bordo e registros fotográficos de cada intervenção. A prática possibilitou a emergência de conteúdos geométricos relacionados a simetria, posição de retas, figuras planas. Percebeu-se a motivação e o interesse dos alunos durante as atividades propostas. Ademais, a cada encontro resgatavam conhecimentos adquiridos e compreendiam novos saberes relacionando a geometria com a arte.
\end{abstract}

Palavras-chave: Geometria. Mandalas. Prática pedagógica.

\begin{abstract}
This article intends to socialize the results of a pedagogical practice developed with students of the 6th grade of Elementary School of a public school, located in Porto Alegre / RS. The objective of the practice was to provide students with activities that relate mathematical content to art, through the construction of mandalas. In addition, we investigated which geometric concepts emerge during the accomplishment of the proposed activities, as well as the reactions of the students during their accomplishment. Data collection was done from the logbook and photographic records of each intervention. The practice allowed the exploration of geometric contents related to symmetry, position of straight lines, plane figures. The motivation and interest of the students during
\end{abstract}

1 Mestranda em Ensino de Ciências Exatas pelo Centro Universitário UNIVATES. Graduada em Ciências Matemáticas - Licenciatura - ULBRA - Campus Cachoeira do Sul - RS. Professora de Ensino Fundamental Anos Finais, na região metropolitana de Porto Alegre, RS. E-mail: marianabsouzars@gmail.com

2 Doutora em Educação pela UNISINOS. Professora do Centro Universitário UNIVATES, RS. E-mail: mtquartieri@univates.br

3 Doutora em Química pela UFSM. Professora do Centro Universitário UNIVATES, RS. E-mail: mimarchi@univates.br 
the proposed activities were perceived. In addition, each encounter rescued acquired knowledge and understood new knowledge relating geometry to art.

Keywords: Geometry. Mandalas. Pedagogical practice.

\section{INTRODUÇÃO}

No decorrer da prática docente, professores demonstram grandes expectativas em relação à aprendizagem dos alunos, bem como algumas decepções quando esse processo de ensinar não ocorre da maneira desejada. Aliado a isto pode-se inferir que o ensino e a aprendizagem, nos tempos de hoje, está passando por um processo de renovação, onde o foco são as metodologias inovadoras, pois educar não é mais simplesmente transferir e receber informações, mas sim é um processo de construção de conhecimentos, estimulando a investigação e participação dos alunos. Portanto, cabe ao professor elaborar alternativas diferenciadas para inovar a sua prática pedagógica. Conforme Massetto (1997, p. 35), "a sala de aula deve ser vista como um espaço de vivência".

No ensino de Matemática, foco de discussão deste artigo, também se observa a necessidade de (re)pensar as metodologias para que o aluno tenha mais interesse por estes conteúdos e obtenha uma aprendizagem com mais sentido e significado. Salienta-se que esta necessidade é importante em todos os níveis de ensino, desde a Educação Infantil até o Ensino Superior. Diante deste contexto, este artigo pretende socializar resultados decorrentes de uma prática pedagógica desenvolvida em uma turma de $6^{\circ}$ ano, Anos Finais do Ensino Fundamental, em uma escola urbana estadual, localizada na Zona Norte de Porto Alegre. A escola conta com 400 alunos matriculados, os estudantes são em sua maioria moradores da comunidade em torno.

O objetivo deste trabalho foi propiciar aos alunos atividades que relacionassem conteúdos matemáticos com o cotidiano, por meio da construção de mandalas. Em especial, foram investigados quais conceitos geométricos emergem durante a realização das atividades propostas. Portanto, a finalidade foi realizar atividades diferenciadas, explorando relações existentes entre um objeto do cotidiano e conceitos matemáticos, em particular aqueles vinculados à geometria. Além disso, o intuito foi investigar as reações dos alunos durante a efetivação das atividades propostas.

Neste contexto, foram proporcionadas atividades que possibilitassem desenvolver habilidades, tais como visualização espacial, a construção de diferentes formas de figuras geométricas planas, ideia de ponto, reta e plano, simetria, ângulos. Bishop (1993 apud Nacarato, 2002) considera a geometria como a "Matemática do espaço". Isso, de certa forma, implica que os professores podem, por meio de ações pedagógicas em sala de aula, oportunizar aos seus alunos a interpretação dos espaços bi e tridimensionais.

Desta forma, procurou-se buscar práticas em que os alunos pudessem manipular materiais didáticos, como o uso de malhas, dobraduras, a construção 
de mandalas, dentre outros. Foram utilizadas atividades que favorecessem o pensamento geométrico por meio de instrumentos manipulativos. De acordo com Pais (2000, p. 13-14), é nas atividades de ensino da geometria, envolvendo o uso de materiais, que é preciso estar "duplamente vigilante para que toda informação proveniente de uma manipulação esteja em sintonia com algum pressuposto racional e, ao mesmo tempo, que todo argumento dedutivo esteja associado a alguma dimensão experimental". Assim, a problemática estabelecida para esta intervenção estava centrada em como a construção de Mandalas pode contribuir na compreensão do pensamento geométrico e propiciar ao aluno o contato da matemática com a prática e o cotidiano?

Na próxima seção, apresentam-se ideias de alguns autores que discutem a relação da geometria com a arte e que embasaram este trabalho.

\section{GEOMETRIA E ARTE}

Ao longo do tempo, o ensino da geometria vem se modificando, pois tem sido entendida como uma disciplina que desenvolve o raciocínio lógico e estabelece novas conexões com o saber.

Os conceitos geométricos constituem parte importante do currículo de Matemática no Ensino Fundamental, porque através deles, o aluno desenvolve um tipo especial de pensamento que lhe permite compreender, descrever e representar, de forma organizada, o mundo em que vive". (BRASIL, 2000, p. 55)

Conforme os Parâmetros Curriculares Nacionais, a Geometria tem um amplo campo para se ensinar situações-problemas onde os alunos se mostram interessados, e estimula-os a observar, explorar, perceber e identificar as diferenças e semelhanças. De acordo com estes Parâmetros, o Ensino da Geometria auxilia na compreensão do espaço físico, proporciona ao educando estímulos de criatividade, facilita a aprendizagem de diferentes conhecimentos aritméticos e algébricos, é uma ciência que favorece a descoberta e a construção do pensamento lógico. Segundo Martins (2008, p. 28),

[...] Sem a Geometria na escola, as pessoas não poderão desenvolver o pensamento Geométrico e nem o raciocínio visual. E por não possuírem tais habilidades, não conseguirão resolver situações em que necessite o pensar geométrico, já que este é facilitador para o entendimento de muitas questões práticas. Além de que a Geometria é uma importante auxiliadora às outras disciplinas, para interpretar um mapa, um gráfico estatístico e até mesmo alguns conceitos de medidas.[...] 
Assim, até Einstein ${ }^{4}$ dizia que a geometria facilitava a comunicação das suas ideias com a evolução de seus pensamentos. $\mathrm{O}$ autor atribuía importância à visão que tinha da geometria e que, sem ela, não teria formulado a teoria da relatividade.

A geometria é o estudo das formas e do espaço, de suas medidas e de suas propriedades. Os alunos descobrem relações e desenvolvem a percepção espacial construindo, desenhando, medindo, visualizando, comparando, transformando e classificando figuras. Utilizam conceitos elementares para construir outros objetos mais complexos como: pontos especiais, retas especiais, planos dos mais variados tipos, ângulos, médias, centros de gravidade de objetos. Sabe-se que a geometria, segundo Ferreira (1999, p. 983, grifos do autor) é

Ciência que investiga as formas e as dimensões dos seres matemáticos” ou ainda "um ramo da matemática que estuda as formas, plana e espacial, com as suas propriedades", ou ainda, "ramo da matemática que estuda a extensão e as propriedades das figuras (geometria Plana) e dos sólidos (geometria no espaço).

Então, pode-se dizer que o desenvolvimento da geometria pode e deve ser estimulado por necessidades práticas de construção do pensamento geométrico. Segundo o PNLD (BRASIL, 2007, p. 15), o pensamento geométrico "surge da interação espacial com objetos e os movimentos do mundo físico, e desenvolvese por meio das competências de localização, de visualização, de representação e de construção de figuras geométricas". Desta forma, vincular a Geometria e a Arte pode constituir uma forma de levar os alunos a um espaço de reflexão, interação e discussão sobre múltiplas relações matemáticas existentes nas diversas áreas de conhecimento, em particular a arte. Conectar a geometria a outras áreas do conhecimento qualifica o aprendizado, capacita o aluno a ter uma visão mais ampla e íntegra, resgatando a Matemática do abstrato para o mundo concreto (BRASIL, 2007).

Para os autores Guimarães e Selva (2004, p. 63), apesar de a geometria estar presente "em diferentes campos da vida humana, seja nas construções, nos elementos da natureza ou nos objetos que utilizamos, e que o mundo é composto por formas geométricas", pode-se considerar que os conteúdos geométricos que estão sendo ensinados nas escolas são distantes dessa realidade. Para os referidos autores é importante a interligação entre geometria e outras áreas do conhecimento, como por exemplo, as artes, uma vez que possibilita a aprendizagem de relações geométricas de forma significativa. Segundo os autores, "o estudo da geometria está, intrinsecamente, relacionado à área de artes, a qual permite uma reflexão nas diferentes formas de expressão, tais como pintura, escultura etc." (GUIMARÃES; SELVA, 2004, p. 63).

A arte é uma das maneiras de representar as coisas do mundo, é através dela que os sonhos passam a se tornar verdades, os desejos são expostos e atingíveis,

4 Albert Einstein físico alemão, nascido em 1879, famoso por ter desenvolvido a Teoria da Relatividade. Tornou-se por este motivo sinônimo mundial de gênio. 
a realidade se faz presente. Da mesma forma que na matemática, a arte também procura interpretar e explicar coisas do mundo. Os Parâmetros Curriculares Nacionais (BRASIL, 1997, p. 55-56) sugerem que o ensino do espaço e da forma "deve ser feito a partir da exploração dos objetos do mundo físico, de obras de artes, pintura, desenhos, esculturas e artesanatos, ele permitirá ao aluno estabelecer conexões entre a matemática e outras áreas de conhecimento". Ademais, a arte é uma forma de comunicação e expressão que possibilita compreensão do mundo em transformação em que o aluno vive. Isso permite que ele desenvolva a criatividade, percepção visual e lógica. Desse modo, pode-se considerar importante a relação entre a geometria e a arte, pois essa afinidade permite o desencadear de reflexões que podem ir para além da sala de aula.

Diante deste contexto, relacionando a geometria com a arte, utilizou-se o tema Mandalas. Os desenhos de Mandalas apresentam uma estrutura diferenciada, que é constituída por desenhos geométricos, formados por eixos simétricos que dividem o espaço em partes iguais que se cruzam no centro do círculo. Na próxima seção, descrevem-se as atividades exploradas, bem como a análise de seus resultados.

\section{RELATO DA PRÁTICA}

Este relato é resultado de uma prática pedagógica realizada a partir da disciplina de Pesquisa em Ensino e Estágio Supervisionado, do curso de Mestrado Profissional em Ensino de Ciências Exatas do Centro Universitário Univates. A proposta foi efetivada com uma turma de $6^{\circ}$ ano, anos finais do ensino fundamental, na qual a primeira autora deste artigo é professora, em Porto Alegre/RS. A turma tinha 30 alunos, com faixa etária entre 10 anos a 12 anos. A intervenção pedagógica transcorreu ao longo de quatro períodos de aula, no mês de maio a junho de 2016, no turno da manhã. Neste contexto, buscou-se enriquecer o ambiente de sala de aula, com o intuito de aperfeiçoar e elaborar metodologias e estratégias para o ensino da geometria nos Anos Iniciais do Ensino Fundamental.

No primeiro momento (da primeira aula), foi apresentada aos alunos a proposta a ser estudada em sala de aula, resgatando alguns aspectos de geometria que já tinham sido desenvolvidos no primeiro semestre de 2016. Foram discutidas ações que pudessem conduzir à prática com informações e sugestões de forma que mobilizasse a turma a participar na construção e execução de Mandalas. Ainda nesta aula, foi solicitado que os alunos fizessem uma pesquisa, a qual poderia ser realizada individualmente ou em duplas. Os educandos poderiam pesquisar em livros, por meio da internet ou até mesmo conversar com os professores de artes da própria escola. As questões que nortearam essa pesquisa foram: Como a arte e a geometria se encontram? O que são Mandalas? Quais são os seus significados? Como é a estrutura de uma Mandala?

$\mathrm{Na}$ segunda aula, os educandos construíram cartazes (Figura 1) sobre os dados encontrados na pesquisa e socializaram os resultados. 
Figura 1. Cartazes de alguns grupos sobre as pesquisas realizadas.

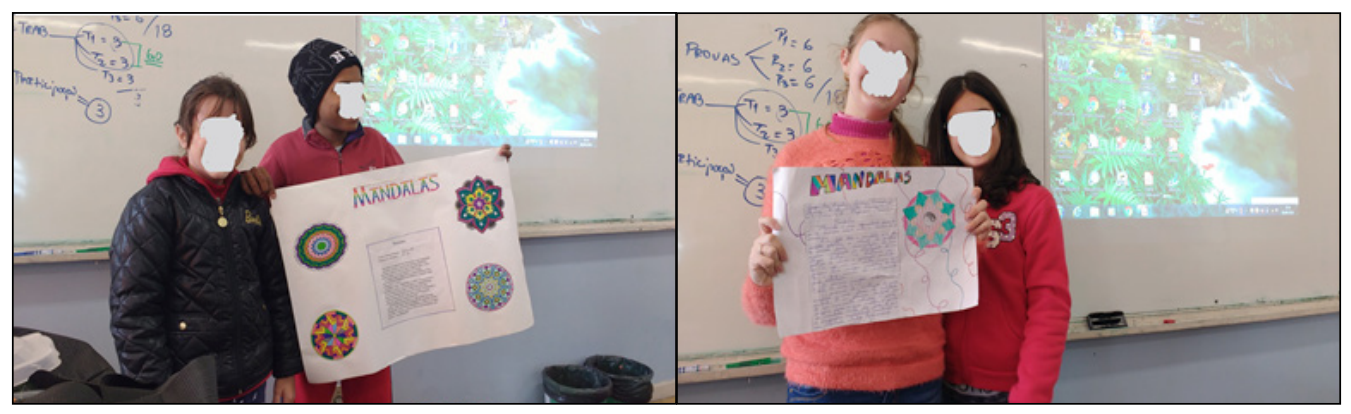

Fonte: dos autores, 2016.

Durante essa aula, houve vários momentos de intervenção da professora para facilitar o entendimento da proposta apresentada. Muitos educandos disseram que já tinham ouvido falar dessa relação da Geometria com a Arte, nas aulas de Educação Artística; outros, ainda, afirmaram que nem sabiam que isso era possível. Alguns ficaram com um olhar de desconfiança, relatando que "a aula de matemática tem que ter cálculos e não realizar atividades diferenciadas". Pires (2000) e Pontes (2003) ressaltam que os professores precisam ter a consciência de que a aquisição de conceitos geométricos deve ocorrer mediante a realização de atividades que envolvam as crianças na observação e na comparação de figuras geométricas.

Após as colocações de todos os grupos, foi iniciada a segunda etapa deste encontro. Solicitou-se que formassem um semicírculo. Então, foi disponibilizada uma folha de papel a cada aluno para iniciar a construção de figuras simétricas. $\mathrm{O}$ processo ocorreu da seguinte maneira:

Desenhando e recortando.

- Dobrar uma folha de papel;

- Desenhar uma das metades da figura (desenho definido pelos alunos);

- Recortar o papel na linha do desenho;

- Desdobrar o papel e, assim, se obtém uma figura geométrica.

$\mathrm{Na}$ figura 2, visualizam-se os procedimentos anteriores. 
Figura 2 - Visualização das etapas do processo de construção das figuras simétricas.

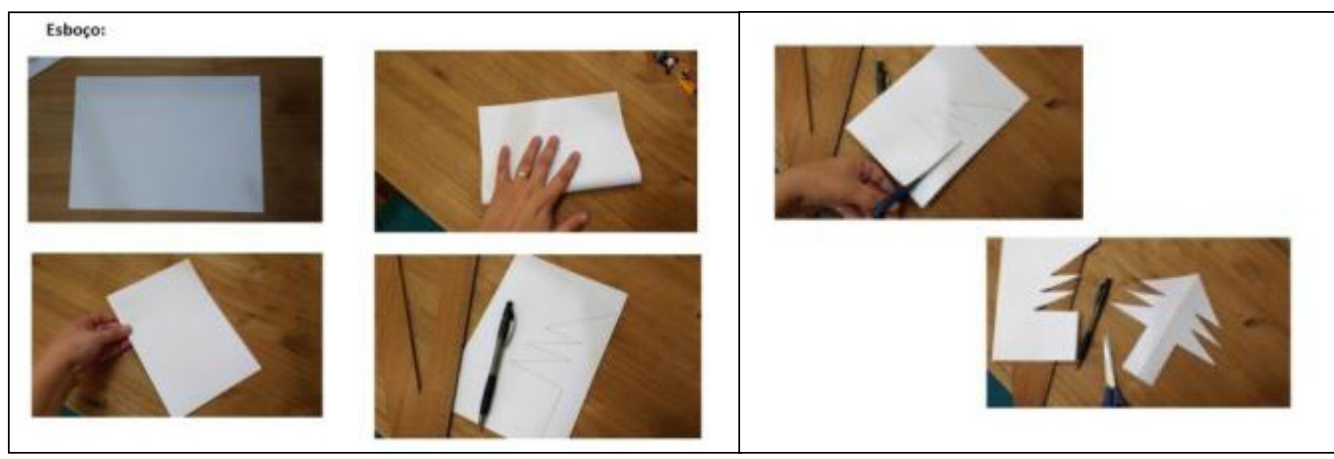

Fonte: dos autores, 2016.

No decorrer das atividades, os alunos ficaram muito motivados, realizando com interesse e envolvimento as tarefas, conforme visualizado na Figura 3.

Figura 3 - Alunos durante o desenvolvimento das atividades

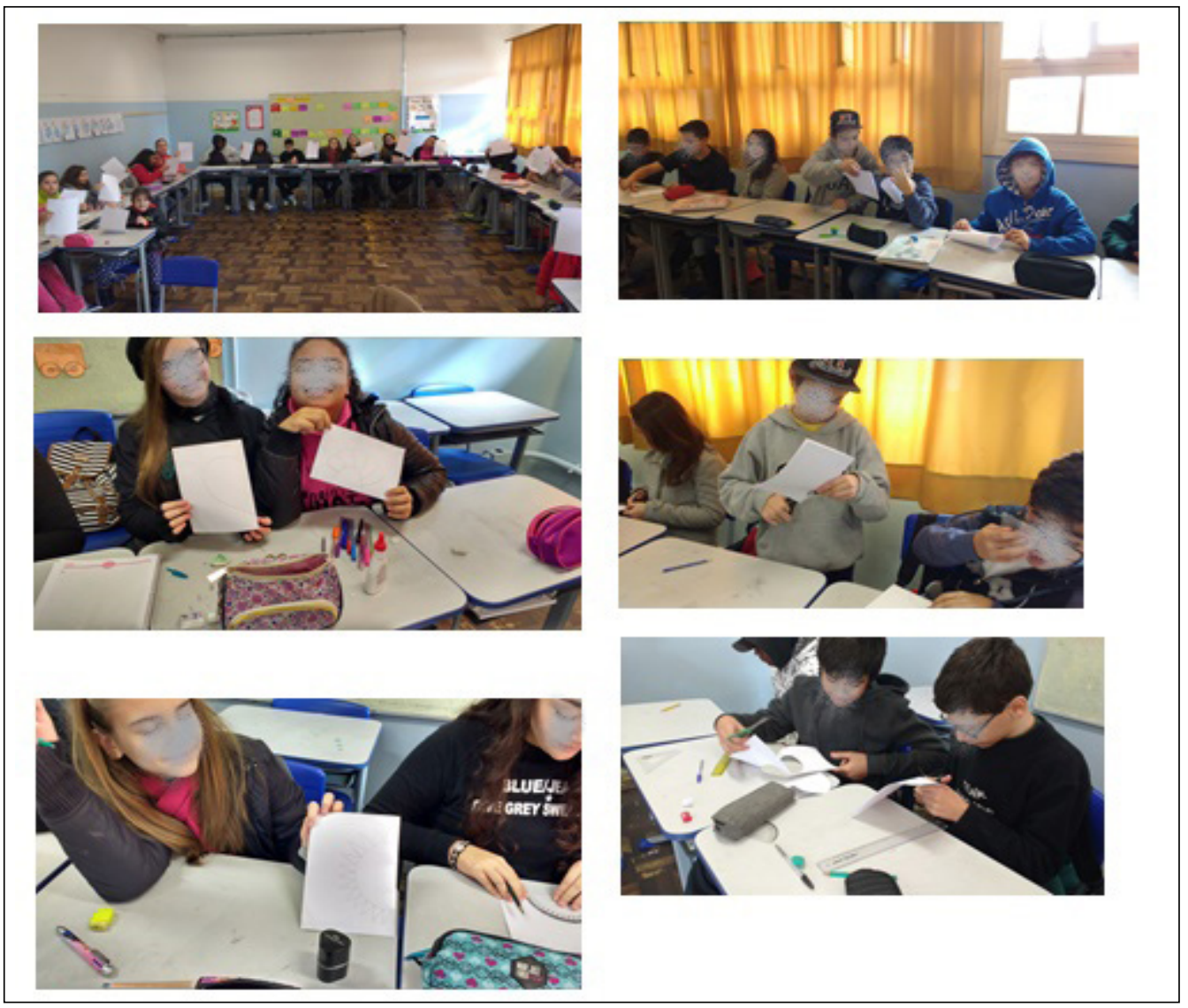

Fonte: dos autores, 2016. 
No decurso desta etapa, a professora acompanhava cada aluno, intervindo somente quando solicitada. Nesse processo, observou-se que alguns alunos demonstravam dificuldades para manusear a tesoura, ou simplesmente, o tracejo para realizar o desenho. Durante essa atividade, surgiram discussões e questionamentos acerca da compreensão da definição de Simetria por meio da prática desenvolvida, abordando os seus diferentes tipos e citando exemplos de onde podemos encontrála cotidianamente. Os demais educandos conseguiram realizar com tranquilidade as atividades propostas neste encontro.

Dando seguimento nesta aula, com o propósito do uso da simetria, disponibilizou-se aos alunos o papel quadriculado, onde deveriam fazer a seguinte construção:

Desenhando em uma malha.

- Desenhar um eixo da simetria e, depois, o desenho da metade de uma figura. Após, completar a outra metade da figura, cuidando para que seja construída de forma simétrica. Segue um exemplo na figura 4.

Figura 4 - Esboço no papel quadriculado da atividade solicitada

\section{Esboço, papel quadriculado:}
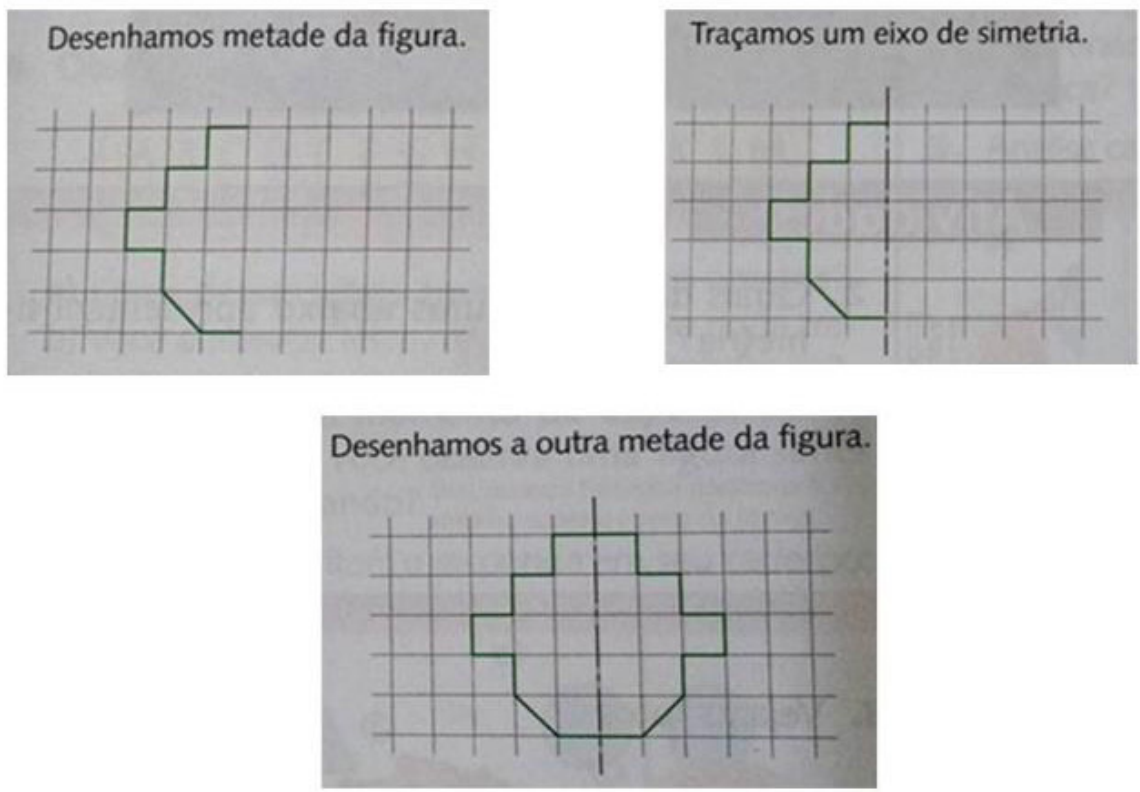

Fonte: Projeto Araribá - Matemática.

$\mathrm{Na}$ Figura 5, aparecem alguns alunos realizando a atividade, representando o empenho e a dedicação para com a atividade proposta. 
Figura 5 - Simetria com papel quadriculado

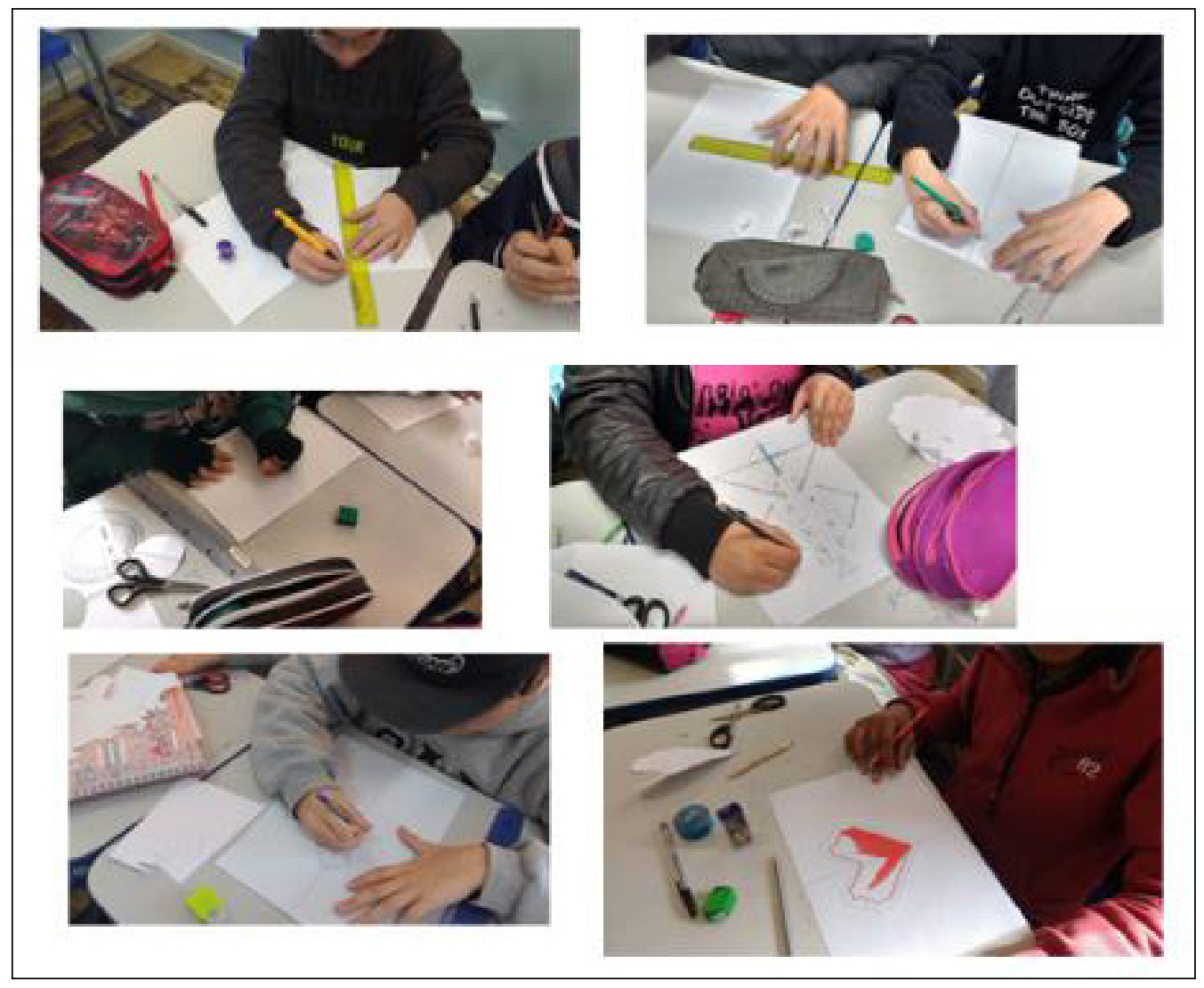

Fonte: dos autores, 2016.

Ao longo desta tarefa, vários desenhos foram surgindo: corações, borboletas, Minions (boneco de um desenho animado), símbolos de super-heróis, desenhos abstratos, dentre outros. Este momento foi tranquilo, pois os alunos fizeram vários desenhos coloridos e criativos. Muitos alunos relataram que gostaram mais dessa segunda tarefa do que da primeira, também disseram que foi um pouco mais difícil no primeiro instante, mas depois conseguiram finalizá-la. Assim, a aprendizagem da geometria em contexto educativo deverá processar-se de um "modo natural, isto é, partindo do que as crianças fazem e observam nas suas experiências, progredindo para níveis mais elevados de compreensão dos conceitos geométricos associados a essas experiências" (MENDES; DELGADO, 2008, p. 13).

No ensino da simetria, podemos fazer o uso de diversos materiais manipulativos, como dobraduras, recortes, embalagens ou logomarcas, que poderão ser usados e explorados para desenvolver de forma mais significativa à compreensão dos conceitos simétricos. São atividades simples que possibilitam o processo de ensino e aprendizagem do educando. 
Ao concluir as atividades, foi realizada uma avaliação da aula com os alunos. Muitos gostaram, expressando que o tempo foi pouco, pois gostariam de fazer outros desenhos no papel quadriculado. Já estavam ansiosos para a próxima aula. Foi solicitado que trouxessem para a aula seguinte instrumentos como tesoura, fita adesiva, caneta hidrográfica, tinta dimensional, tinta guache e pincel.

No terceiro encontro, os alunos foram divididos em seis equipes e receberam um papel - cartão (sulfite) com dimensões $16 \mathrm{~cm} \times 16 \mathrm{~cm}$, trabalhando-se a simetria com dobraduras. Foi usada a expressão "fazer uma dobradura" como o ato de dobrar, uma transformação do plano. O termo dobra ou vinco é usado para a marca no papel resultante da dobradura. Na geometria das dobraduras, dobrar significa sobrepor pontos e obter a reta de dobra, que é o lugar dos pontos que permanecem fixos.

Como a turma era composta por 30 alunos, para que ficasse mais fácil de executar os passos da dobradura, foi projetado, em slides, o processo de construção da dobradura. Novamente, resgataram-se aspectos desenvolvidos na aula anterior, descrevendo e questionando quantos eixos seriam formados em cada caso.

No processo de construção desta atividade, inicialmente, os alunos deveriam dobrar o pedaço de papel sulfite, como mostram as imagens da Figura 6. E, após, seguir os seguintes procedimentos:

$1^{\circ}$ Criar desenhos nas bordas. Em seguida, recortar, obtendo um molde.

$2^{\circ}$ Desdobrar o sulfite e fixar sobre o papel-cartão com a fita adesiva.

$3^{\circ}$ Com a caneta hidrográfica, contornar o molde sobre o papel-cartão.

$4^{\circ}$ Aplicar a tinta dimensional nos contornos, deixando secar.

$5^{\circ}$ Pintar o interior dos desenhos com tinta guache. 
Figura 6 - Etapas da construção da atividade de dobradura

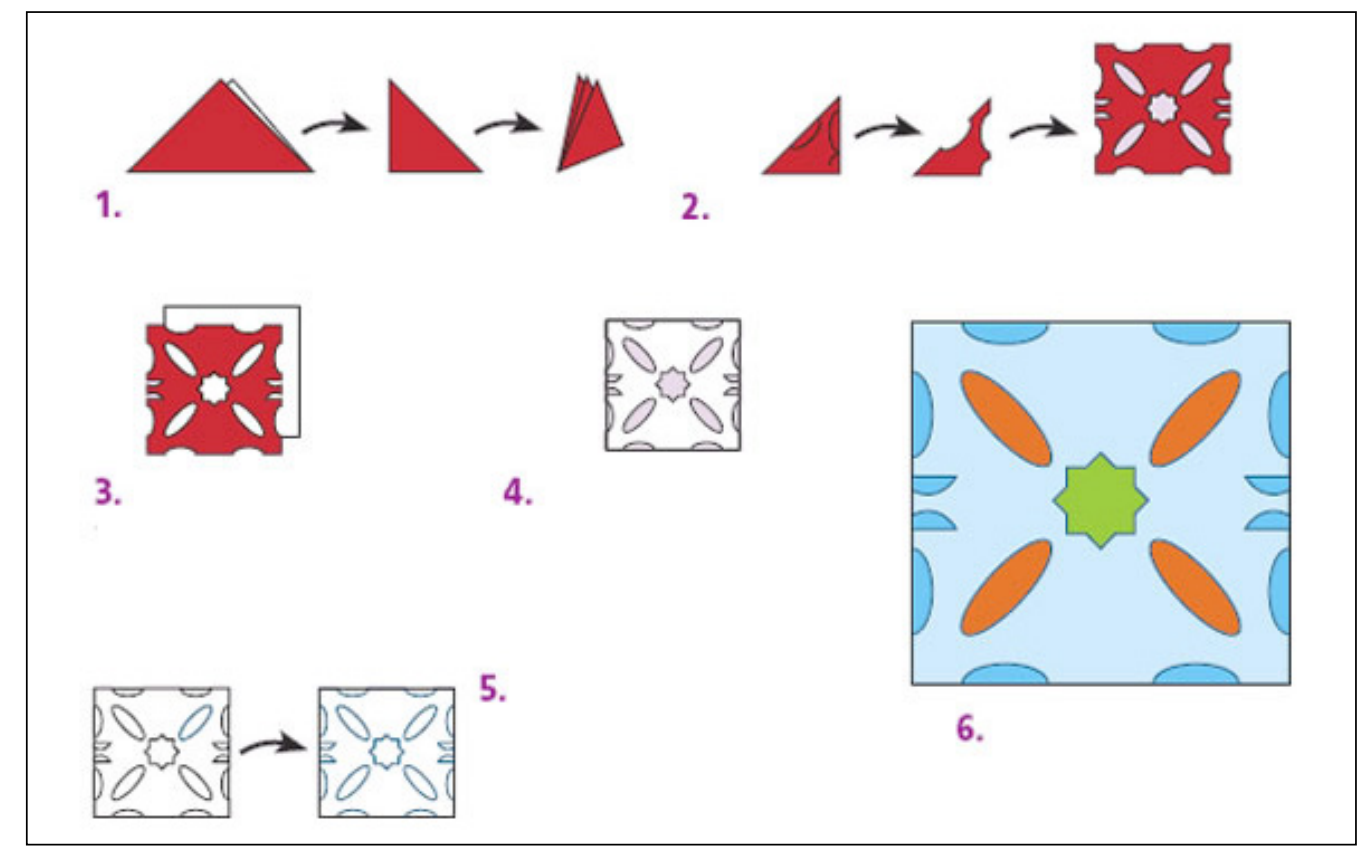

Fonte: Simetria com dobradura. Revista Guia Fundamental, 2010. Disponível em: <http:// revistaguiafundamental.uol.com.br/professores-atividades/85/artigo215236-2.asp>.

A maioria dos alunos desenvolveu a atividade tranquilamente, mas alguns tiveram dificuldades para fazer as dobras. Como a professora não estava conseguindo atender a todos, os educandos que já tinham terminado de dobrar, ajudavam os outros a realizar a tarefa. $\mathrm{Na}$ figura 7 , há algumas construções dos alunos. 
Figura 7 - Imagem dos alunos construindo suas dobraduras

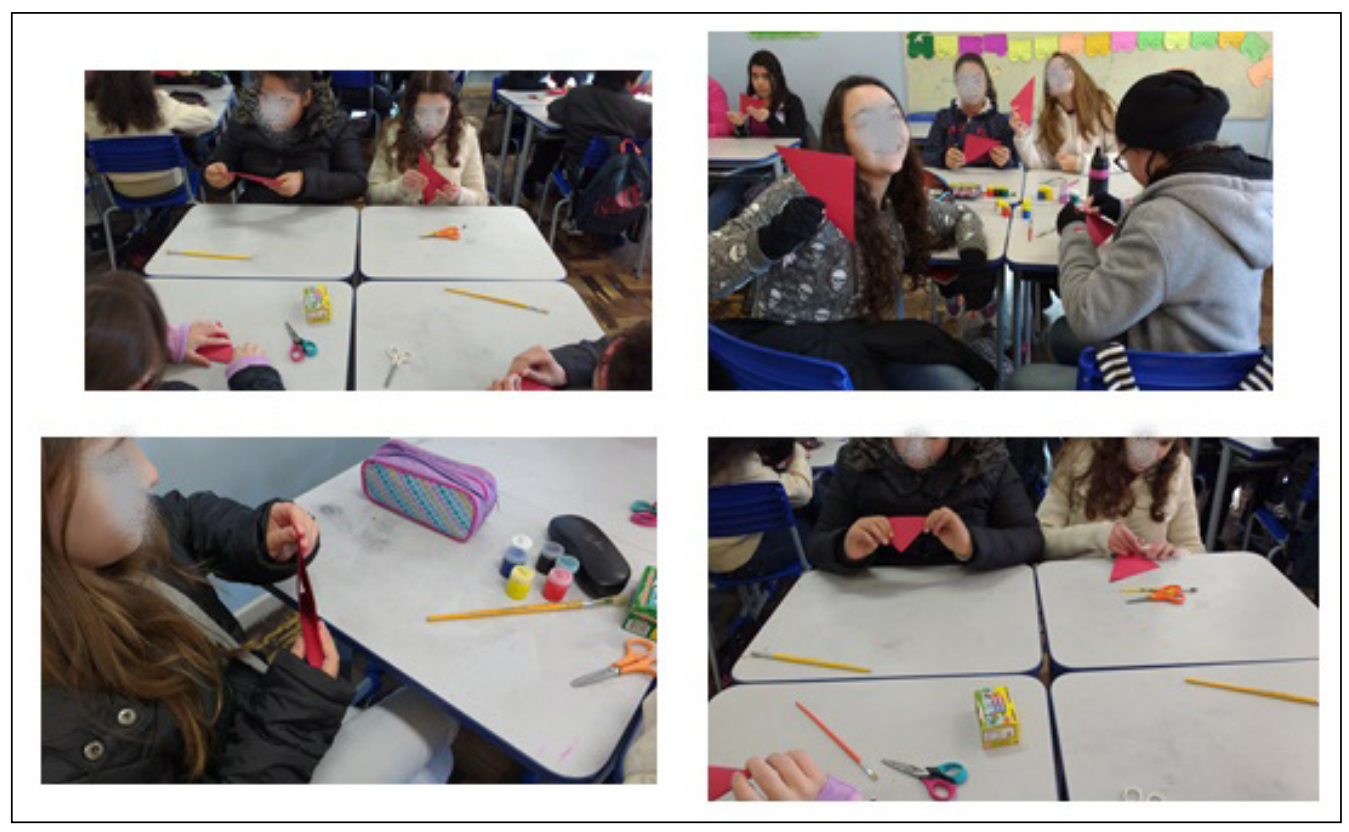

Fonte: dos autores, 2016.

Durante a execução da atividade, observou-se o processo de construção dos grupos. À medida que iam finalizando a dobradura, já começavam a recortar e dar forma. Muitos abriam, verificavam o que estava sendo formado, dobravam novamente e faziam mais recortes. Relacionaram os desenhos formados com ladrilhos, como se fossem azulejos. Muitos alunos tracejaram com lápis os eixos formados, evidenciando que todos os lados haviam ficado simétricos. Na figura 8, há imagens de algumas figuras construídas. 
Figura 8 - Algumas dobraduras construídas pelos alunos.
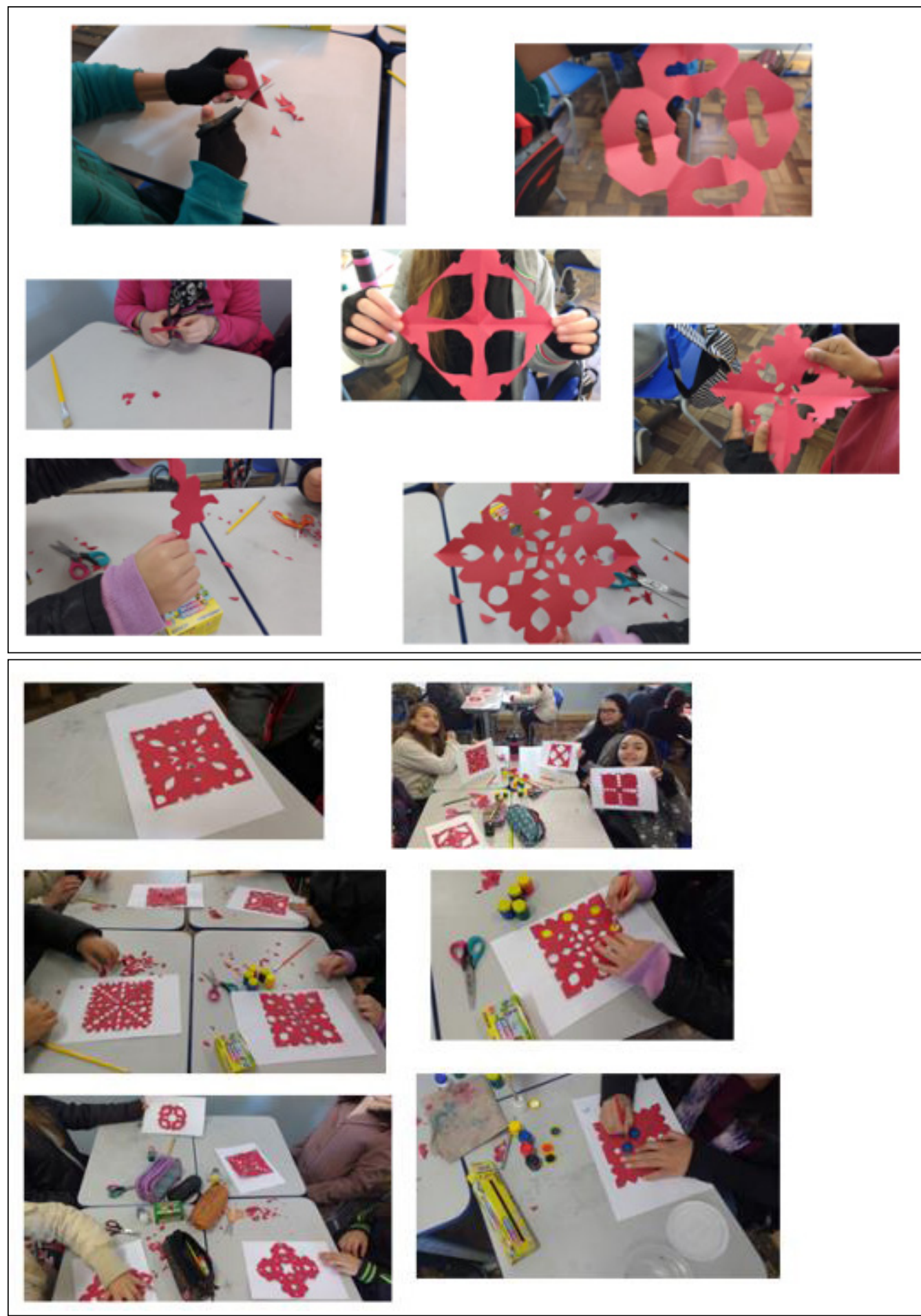

Fonte: dos autores, 2016. 
Nesta etapa, todos os alunos conseguiram executar a atividade proposta. À medida que a turma encerrava a atividade, começaram a organizar o mural para expor os trabalhos desenvolvidos. Os educandos escolheram como deveriam ficar os ladrilhos, tanto o tamanho como as cores. $\mathrm{Na}$ Figura 9, encontram-se os passos para a construção do mural.

Figura 9 - Construindo o mural da escola

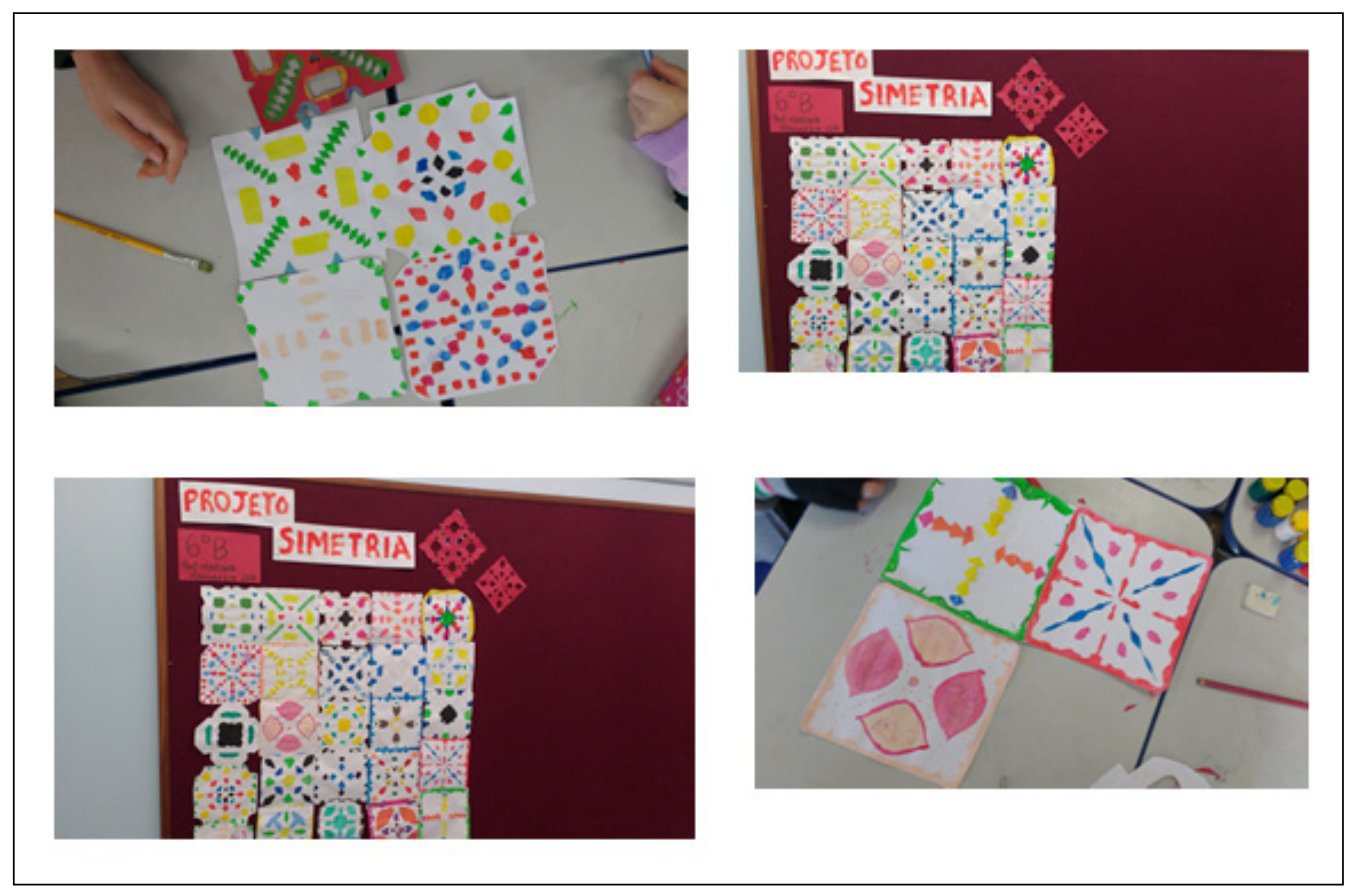

Fonte: dos autores, 2016.

Ao encerrar esse encontro, foi realizada novamente uma avaliação, perguntando o que eles acharam da proposta realizada em sala de aula. Eles relataram ter sido bacana e que ficaram felizes com os colegas que são considerados mais agitados, por eles não terem prejudicado a aula e a atividade.

Salienta-se que, no decorrer desta abordagem, procurou-se despertar a atenção dos alunos para o processo da dobradura, a quantidade de eixos formados ao longo da execução, a percepção dos mesmos em relação às estratégias geométricas utilizadas, a localização e o deslocamento no plano, a observação e noções de ângulos formados a partir da dobradura. Neste momento, foi feita uma interferência realçando as características que formam um ângulo, se é possível medir os mesmos, quais elementos geométricos são necessários para a construção de um ângulo, trazendo para a discussão o conceito de ângulos de forma intuitiva.

De acordo com os PCNs (BRASIL, 1997), o ensino da geometria pode levar o aluno a estabelecer relações entre a Matemática e outras áreas, se partir da exploração de objetos do mundo físico, como obras de artes, pinturas, desenhos, 
esculturas e artesanato. Assim, é importante instigar a criatividade no processo de ensino, propondo atividades com dobraduras, modelagem de formas, construção de materiais concretos, entre outras.

Os PCNs ainda destacam a importância de atividades de visualização de formas geométricas na natureza e nas criações humanas.

Uma das possibilidades mais fascinantes do ensino da Geometria consiste em levar o aluno a perceber e valorizar sua presença em elementos da natureza e em criações do homem. Isso pode ocorrer por meio de atividades em que ele possa explorar formas como as de flores, elementos marinhos, casa de abelha, teias de aranha, ou formas em obras de arte, esculturas, pinturas, arquitetura, ou ainda em desenhos feitos em tecidos, vasos, papéis decorativos, mosaicos, pisos etc. (BRASIL, 1997, p. 128).

Para Luckesi (1994), o conhecimento adquirido na escola só é significativo e real para os alunos, se for assimilado pela compreensão, exercitação e utilização criativa. Portanto, cabe ao professor buscar estratégias que colaborem para potencializar as capacidades criativas de seus educandos, explorando conceitos e propriedades geométricas, promovendo-lhes a oportunidade de compreender sua utilidade no cotidiano, na matemática e em outras ciências.

No quarto e último encontro desta prática pedagógica, foram construídas as Mandalas. Os educandos se dividiram em equipes, sendo disponibilizados aos alunos palitos de churrasco e alguns novelos de lã. Esse foi o encontro mais esperado por eles, pois estavam ansiosos para desenvolver esta última etapa do projeto, a construção das Mandalas. Muitos apresentavam receio de não conseguirem realizar com êxito a atividade. Para facilitar esse processo, novamente foi projetado, em slides, o passo a passo. Na figura 10, visualização dos procedimentos.

- Cada aluno recebeu dois palitos de churrasco. Foram instruídos a medir ambos, para que ficassem no mesmo comprimento, caso houvesse diferença de tamanho, deveriam utilizar a tesoura para alinhar.

- Após a verificação do tamanho dos palitos, deveriam deixar ambos paralelos e com um fio do novelo de lã dar um nó no meio das duas varetas. Em seguida, abrir os dois palitos formando uma cruz.

- Com os palitos em formato de cruz, costurar entre as varetas, formando um desenho geométrico. Neste processo, podem-se usar diferentes cores de lãs. 
Figura 10 - Etapas para a construção das Mandalas

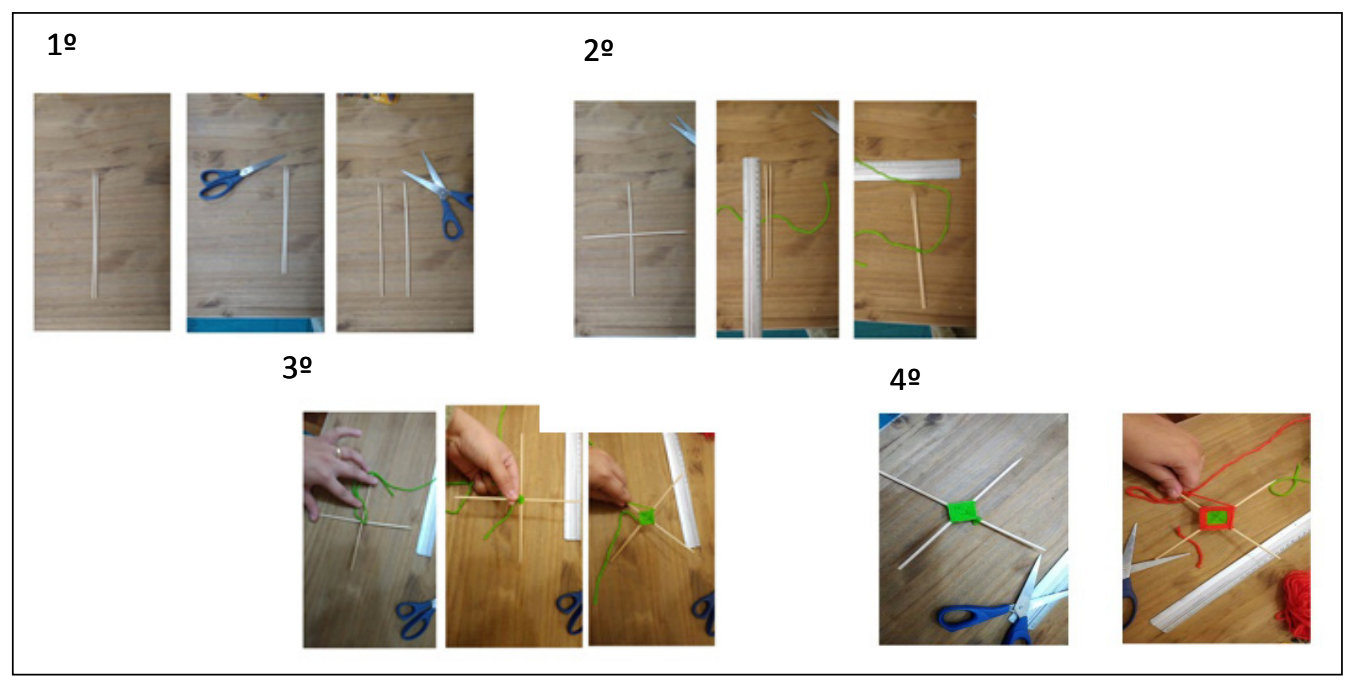

Fonte: dos autores (2016).

Esse processo foi o mais turbulento de todos, pois eram muitos alunos para atender e auxiliar durante a prática. A etapa mais difícil e mais demorada foi a dos palitos em forma de cruz. Depois que começaram a trançar com os novelos de lã, a turma se concentrou. Muitos alunos apresentaram dificuldades para iniciar o processo de tecer as Mandalas. Havia uma aluna que já sabia como fazer, então ajudou os demais alunos nesta etapa. Na figura 11, é possível visualizar os alunos tecendo as Mandalas. 
Figura 11 - Alunos tecendo as Mandalas

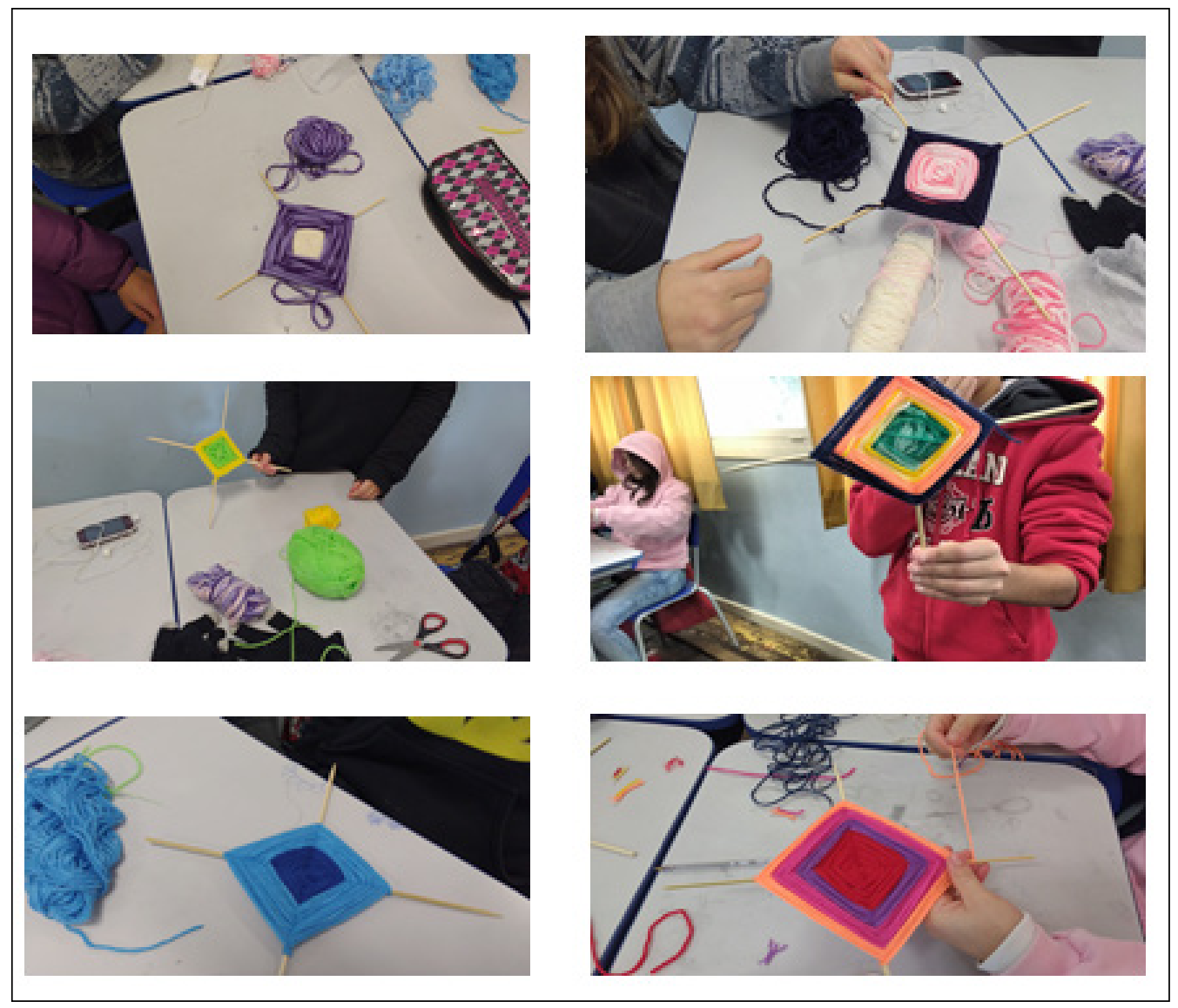

Fonte: dos autores, 2016.

Quando os educandos compreenderam o processo de tecer as Mandalas, o trabalho fluiu tranquilamente. Resgataram a importância das cores, as quais apresentaram no primeiro encontro. Alguns escolheram cores específicas para trabalhar a harmonia. Como já se imaginava que, talvez, pudessem faltar novelos de lã, foi disponibilizada uma caixa de novelos com cores sortidas.

Ao longo desta construção, foram discutidos os elementos geométricos utilizados, tais como: quantos eixos foram formados? Que tipos de ângulos apareceram nesta etapa? Seria possível construir uma Mandala com mais eixos? Quais estratégias seriam utilizadas? Ao tecer a Mandala, que formas geométricas apareceram?,

Ainda nessa construção, outros questionamentos foram surgindo: os significados das Mandalas, quais as dificuldades encontradas no decorrer da atividade, o porquê das cores, se pudéssemos acrescentar mais duas retas, será que seria viável, qual forma tornaríamos. Também foram discutidas questões relacionadas aos eixos 
de simetria, como por exemplo, se fossem usados mais eixos que formato a figura teria. Nessa etapa, pôde-se observar a importância da manipulação e exploração de materiais concretos no espaço de sala de aula, o quanto esse processo pode estimular o aluno a compreender de forma mais abstrata os conceitos geométricos básicos. Fainguelent (1999, p. 51), destaca que:

[...] o ambiente geométrico possibilita ao aprendiz desenvolver suas impressões sobre a estrutura matemática, necessitando basear-se em um ambiente real para interagir. Já em um estágio mais avançado, esse ambiente geométrico adquire um significado mais amplo, não precisando de um ambiente real (concreto) que o fundamente. O aprendiz já compreendeu e produziu um significado que, partindo de um número reduzido de axiomas, postulados e definições, pode constituir, por via dedutiva, um conjunto de apropriações geométricas [...].

Durante esse processo, alguns alunos observaram que se eles tencionassem mais o fio de lã, deixariam a Mandala mais firme. Logo que foram finalizando, uns solicitaram se podiam construir mais Mandalas. Assim, surgiram Mandalas lindas, coloridas e com acabamentos melhores. Ao final, foi solicitado que reunissem todas as Mandalas prontas a fim de exporem as obras criadas (Figura 12) para toda a comunidade escolar. Entretanto, esse processo não foi possível, pois os educandos não deixaram realizar uma exposição do trabalho desenvolvido, pois queriam levar as suas Mandalas para casa e mostrar o que foi desenvolvido para os seus responsáveis. 
Figura 12 - Exposição de algumas Mandalas construídas.

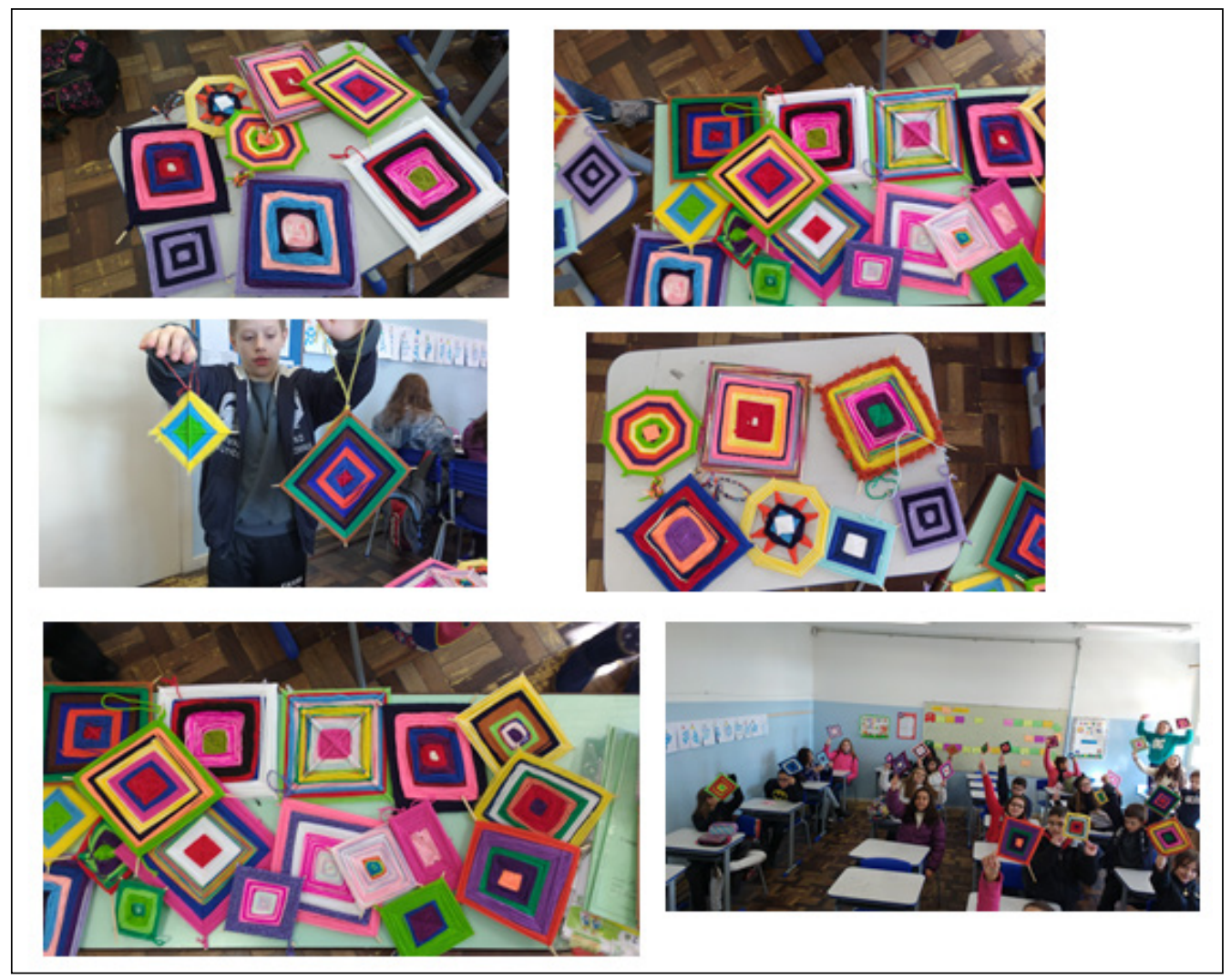

Fonte: dos autores, 2016.

Finalizando esta proposta com os alunos, foi efetivada novamente uma avaliação em conjunto sobre o trabalho desenvolvido, verificando o que os educandos acharam das aulas com o uso de Mandalas e Geometria. Os relatos foram positivos, os educandos queriam continuar na aula seguinte, fazendo outros modelos. Destacaram também que todas as aulas de matemática deveriam ser sempre assim, pois eles não percebiam o tempo passar. Quando perguntados sobre os conhecimentos geométricos apreendidos, muitos disseram que agora entendiam o que seria simetria, a representação no plano, os tipos de retas, os ângulos formados, a quantidade de eixos da simetria e que a matemática está ligada em diversos aspectos da natureza. Ressalta-se assim, em concorde com Fainguelernt (1999), que o ensino da Geometria deve partir da percepção e intuição de dados concretos e experimentais, explorando os conceitos, representações e aplicações, desenvolvendo o raciocínio lógico, para chegar ao processo de abstração. 


\section{RESULTADOS E DISCUSSÓES}

Nesta prática pedagógica, realizada em uma turma do $6^{\circ}$ ano do Ensino Fundamental, percebeu-se que a manipulação de materiais didáticos despertou o interesse dos alunos aos aspectos relativos ao ensino da geometria. Em decorrência, como expomos nas seções anteriores, mesmo que os alunos demonstrassem algumas dificuldades na execução das atividades propostas, as discussões que deles advieram, mostraram a possibilidade de efetivá-las.

Assim, muitos aspectos foram observados, pois alguns educandos conseguiram distinguir os conceitos de simetria, eixos da simetria, representação no plano, os tipos de reta e os ângulos formados e, também redescobriram uma maneira diferente de compreender o conhecimento geométrico ao longo de cada atividade, surgindo novos saberes que foram se constituindo, tornando cada processo significativo.

A atividade de construção e manipulação dos materiais estimulou a compreensão do ensino da geometria, em particular quanto aos conceitos de simetria, construção de figuras planas, posição de retas. As atividades propostas possibilitaram a interação do aluno em cada etapa efetivada. Além disso, foi proporcionado aos alunos o desenvolvimento da capacidade de olhar, comparar, medir, generalizar e abstrair, pois em cada situação proposta instigava-se os alunos para tais habilidades. E, conforme Bulos (2011, p. 5) enfatiza "a geometria pode ser o caminho para desenvolvermos habilidades e competências necessárias para a resolução de problemas do nosso cotidiano".

No decorrer de cada encontro foi discutida a interação com a arte e os conceitos geométricos. À medida que os alunos compreendiam a simetria, conseguiam interligar com a construção das Mandalas. Também foi possível evidenciar indícios de aprendizagem em relação aos conhecimentos geométricos pretendidos nessa prática pedagógica, tais como eixos formados a partir da dobradura, os ângulos, as posições de retas, construção de figuras planas. O trabalho com as dobraduras permitiu aos alunos uma abordagem de compreensão mais significativa que contribuiu para a construção do pensamento geométrico.

Cada encontro serviu de motivação para o próximo, o que gerava uma expectativa maior para a elaboração das Mandalas. Foi perceptível o entusiasmo com que os alunos realizaram cada processo de aprendizagem. Sempre preocupados em finalizarem cada etapa e, quando um dos colegas não conseguia executar a tempo, estavam a todo o momento dispostos a ajudar um ao outro, sendo esta, uma das características forte da turma, a colaboração com o próximo. Ao destacar este processo de interação, Van Walle (2009, p. 49) ressalta que o "pensamento reflexivo e, consequentemente, a aprendizagem, são enriquecidos quando o estudante se compromete e se envolve com os outros explorando, todos juntos, as mesmas ideias". Por fim, pode-se inferir que os alunos conseguiram compreender os conceitos geométricos presentes na construção das Mandalas, resgatando a cada encontro conhecimentos adquiridos e relacionando o ensino da geometria com a arte. 


\section{REFERÊNCIAS}

BULOS, Adriana Mascarenhas Mattor. O ensino da Geometria nos anos iniciais do ensino fundamental. In: XII CIAEM - ACME, Recife, Brasil, 2011.BRASIL. Ministério da Educação e do desporto. Secretaria de Educação Fundamental - Referencial Curricular Nacional para a Educação Infantil - Brasília: MEC/SEF, V. 3, 2000.

BRASIL. PNLD - Guia do livro didático 2007: Matemática: séries/anos iniciais do ensino fundamental. - Brasília: Ministério da Educação, Secretaria de Educação Básica, 2007.

BRASIL. Parâmetros Curriculares Nacionais. Brasília, MEC/SEF, Matemática - V. III: Primeiro e segundo ciclos do Ensino Fundamental, 1997.

FAINGUELENT, E. K. Educação Matemática: representação e construção em geometria. Porto Alegre: Artes Médicas Sul, 1999.

GUIMARÃES, G. L; SELVA, A. C. V.. - Educação infantil e matemática - Proposta Curricular do Município de Olinda, 2004.

LORENZATO, S. Por que não ensinar geometria? A educação matemática em revista. n. 4. (1ºmestre), 1995. p. 3-11.

LUCKESI, C. C. Filosofia da Educação. São Paulo: Cortez, 1994.

MASSETTTO, M. T.. Didática: A aula como centro. São Paulo: FTD, 1997.

MARTINS, L. F. . Motivando o ensino da geometria. Monografia de Pós- graduação da Universidade o Extremo Sul Catarinense - UNESC, Dezembro, 2008.

MENDES, M. F.; DELGADO, C. C. . Geometria: textos de apoio para educadores de infância. Lisboa: Direcção-Geral de Inovação e de Desenvolvimento Curricular, 2008.

NACARATO, A. M. Educação continuada sob a perspectiva da pesquisa-ação: currículo em ação de um grupo de professoras ao aprender ensinando geometria. Tese. Universidade de Campinas, Campinas, 2000.

PAIS, Luiz Carlos. Intuição, Experiência e Teoria Geométrica. Zetetiké, Campinas, SP, v. 4, n. 6, p. 65-74, jul./dez. 2000.

Projeto Araribá: matemática / obra coletiva, concebida, desenvolvida e produzida pela Editora Moderna; Editora Responsável Juliane Matsubara Barroso. - 1. Ed.-São Paulo: Moderna, 2006.

PIRES, C.; CURI, E.; CAMPOS, T. Espaço e forma: São Paulo, PROEM Editora. 2000. PONTE, J. P.; BROCARDO, J.; OLIVEIRA, H. Investigações Matemáticas na Sala de Aula. Belo Horizonte: Autêntica, 2003.

VAN DE WALLE, J. A. Matemática no ensino fundamental: formação de professores e aplicação em sala de aula. Tradução de Paulo Henrique Colonese.6.ed.Porto Alegre: Artmed, 2009. 